\title{
Sistem Analistlerinin Dijital Çă̆ ile Birlikte Değişen Rolleri ve Kullandıkları Yeni Yöntemler
}

\author{
Ceren Çubukçu \\ Maltepe Üniversitesi, Mühendislik Fakültesi, Bilgisayar Mühendisliği
}

Geliş Tarihi: 2015-12-21 Kabul Tarihi: 2016-06-13

\section{$\ddot{O ̈ z}$}

\begin{abstract}
Günümüzde internet ve mobil teknolojilerin gelişmesi ve yaygınlaşmasıyla beraber bilgiye erişim oldukça kolaylaşmış ve ucuzlamıştır. Bu da aşırı bilgi yüklemesi ve büyük veri gibi kavramları beraberinde getirmiştir. $\mathrm{Bu}$ kavramlar ise sistem analistlerinin rollerinde değişiklikler olmasına neden olmuştur. Ayrıca internet ve mobil teknolojilerdeki ilerlemelerle beraber sistem analistlerinin Sistem Geliştirme Yaşam Döngüsü adımlarında kullandıkları yöntemler de değişmiştir ve ileride daha da değişecektir. Bu çalışmada bu gelişmeler ve ortaya çıkan yeni kavramlar sonucu sistem analistlerinin üstlenmeye başladıkları yeni roller ve analistlerin aktif olarak görev aldıkları planlama, analiz ve tasarım aşamalarında kullanmaya başladıkları ve ileride kullanmaya başlamaları gerekli olan yeni yöntemler açıklanmıştır. Sonuç olarak, gelecekte sistem analistlerinin rolü daha çok strateji odaklı olacaktır ve veri analisti gibi çalışacaklardır. Ayrıca büyük veriyi analiz edebilmek için yeni yöntemler kullanacaklardır.
\end{abstract}

Anahtar Kelimeler: Sistem Analizi, Sistem Analisti, Sistem Geliştirme Yaşam Döngüsü, Büyük Veri, Yazılım Geliştirme

\section{The Changing Roles of Systems Analysts with Digital Era and the New Methods Systems Analysts Use}

\author{
Ceren Çubukçu \\ Maltepe University, Faculty of Enginering, Department of Computer Engineering
}

\begin{abstract}
Nowadays, along with the development of internet and mobile technologies, the access to information has become easier and cheaper. This brought along the concepts of information overload and big data and these concepts have led to changes in the roles of systems analysts. Moreover, along with the development of internet and mobile technologies, the methods which systems analysts use in the steps of Systems Development Life cycle have changed and will change even more in the future. In this study, as a result of these developments and emerging concepts, the new roles that systems analysts start to take on are discussed. Systems analysts contribute the most during the planning, analysis and design phases. Therefore, the new methods which systems analysts start to use or will have to start to use in the future during the planning, analysis and design phases are also explained. As a result, the roles of the systems analysts in the future will be more focused on strategy and they will work as a data analyst rather than a system analyst. They will also use new methods to analyze big data.
\end{abstract}

Keywords: Systems Analysis, Systems Analyst, Systems Development Life Cycle, Big Data, Software Development

\section{Giriş}

Sistem Geliștirme Yaşam Döngüsü Şekil 1'de gösterildiği üzere planlama, analiz, tasarım, kodlama, test ve sistemin teslim edilmesi adımlarından oluşmaktadır. Sistem analistleri ise bu yaşam döngüsünün neredeyse tüm aşamalarında rol alırlar fakat en aktif olarak rol aldıkları bölüm ise planlama, analiz ve tasarım aşamalarıdır. Sistem analizinin temel görevi kullanıcılarla görüşüp sistem gerekliliklerini anlamak, sistemin kapsamını belirlemek, sistem tasarımı yapmak ve mevcut sistemi analiz etmektir [1]. İnternetin ve mobil teknolojilerin gelişmesiyle beraber son yıllarda

*Sorumlu Yazar: Adres: Maltepe Üniversitesi, Mühendislik Fakültesi, Bilgisayar Mühendisliği, İstanbul, Türkiye, E-mail: ceren.cubukcu@gmail.com 
sistem analistlerinin görevlerinde de değişiklikler olmuştur. $\mathrm{Bu}$ değişimin en büyük nedenlerinden biri ise artık bilgiye erişimin oldukça kolaylaşmasıdır. Fakat bilgiye erişimin kolaylaşması aşırı bilgi yüklemesi veya büyük veriyle başa çıkma gibi sorunları da beraberinde getirmiştir. Bu sorunlar da sistem analistinin işinin en önemli parçası olan veriyi ve bilgiyi analiz etmeyi zorlaştırmıştır.

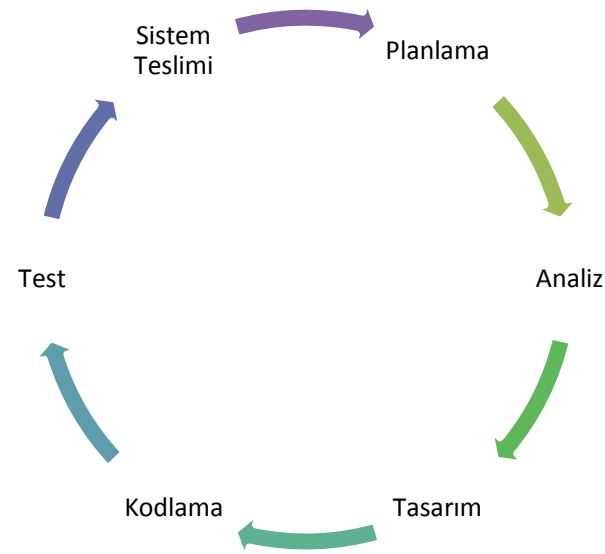

Şekil 1. Sistem Geliştirme Yaşam Döngüsü

Butcher'a göre aşırı bilgi yüklemesinin evrensel olarak kabul edilmiş bir tanımı yoktur çünkü birkaç durumu ifade edebilir [2]. Örneğin, birinin sindirebileceğinden daha çok bilgiye sahip olması veya istenilenden daha çok bilgiye sahip olunması ama bu bilgilerin sadece bir kısmının amaca uygun nitelikte olması aşırı bilgi yüklemesinin tanımlarından bazılarıdır [2]. Feather'a göre de aşırı bilgi yüklemesi, birinin etkili bir biçimde kullanabileceğinden daha çok bilgiye sahip olması şeklinde özetlenebilir [3].

Son zamanlarda yapılan çalışmalarda görüldüğü üzere büyük veri ise şirketler ve toplum tarafından üretilen ve hızlı bir biçimde büyüyen yapısal veya yapısal olmayan verinin yönetilmesi, analiz edilmesi ve görüntülenmesi için gelişen bir teknoloji olarak adlandırılmaktadır [4]. Büyük veriyi oluşturan veriler genellikle internetteki tıklamalardan, mobil telefonlar yoluyla yapilan konuşmalardan, sosyal medyada bireyler tarafindan üretilen içeriklerden ve yine internet üzerinden veya mağazalardan yapılan satın alma işlemleri tarafindan oluşturulmaktadır [5].

Bu çalışmada sistem analistleri için doğru sorularla doğru veriye ulaşmanın ve ulaşılan bu verilerin iyi analiz edilmesinin önemi vurgulanmıştır. Çalışmanın ikinci bölümünde sistem analistlerinin dijital çağın gelişmesiyle beraber değişen rolleri ve oluşan yeni görevlerinden, sonraki bölümde ise sistem geliştirme yaşam döngüsü aşamaları sırasında kullandıkları yeni yöntemlerden ve son olarak da sonuçlardan bahsedilmiştir.

\section{Sistem Analistlerinin Yeni Rolleri}

İş hayatında bilgi kurumlar için başarının anahtarı olarak görülmektedir ve pek çok kişi işleri gereği birçok kaynaktan gelen boğucu derecede çok bilgiyle baş etmek zorunda kalmaktadır [6]. Sistem analistleri için ise bu durum daha da fazla boğucudur ve dikkat edilmezse bu aşırı bilgi yüklemesi onlar da strese ve fiziksel sağlık sorunlarına yol açabilmektedir [6]. Bu nedenle sistem analistlerinin sadece işlerine yarar bilgilere erişebilmek için doğru soruları sormaları gerekmektedir. Aşağıda bu sorulara birkaç örnek verilmiştir [7]:

1) Problemi nasil tanımliyorsunuz?

2) Neye ihtiyacınız var?

3) Problem nereden kaynaklanıyor?

4) Varsayımlarınız neler?

5) Yeni sistemde mevcut sistemden farklı neler olmasını istiyorsunuz?

Sistem analistlerinin bilgi teknolojilerinin şimdiki kadar gelişmesinden önce de analiz için sorduğu sorular önemliydi ancak etrafımızda olan aşırı bilgi yüklemesiyle baş edebilmek için doğru soruları sormak ve bu sorulardan edindiğimiz bilgilere göre doğru yorumlar yapmak sistem analistleri için her zamankinden daha önemlidir. Katzer ve Fletcher'e göre ikilem çok açıktır: çok fazla bilgiye sahibiz fakat aynı zamanda yeterli düzeyde doğru bilgiye sahip değiliz [8]. Bu yüzden sistem analistleri için günümüzde en önemli kabiliyetlerden biri doğru soruları sorup doğru cevapları alabilmektir. Ayrıca bu aldığı cevapları iyi yorumlayıp onları öncelik sırasına göre düzenleyebilmeli ve karşısına ilgi uyandırıcı bir biçimde aktarabilmelidir. Badenoch'un da belirttiği gibi bilgi tek başına kullanışlı değildir, bir filtreleme mekanizmasına ihtiyaç duyar [9]. O filtreleme mekanizması da sistem analistinin kendisidir.

Bilgisayarların işlemci hızları son 30 yıldır her geçen yıla göre daha da hılanmaktadır ve bu değişim hızı sürekli olarak insanların üzerindeki değişime ayak uydurma baskısını da arttırmaktadır [6]. İşin ilginç yanı, bilgisayarlarla gelen otomatikleşmenin bize daha çok boş zaman kazandırmak yerine her şeyi daha hızlı yapmamız için üzerimizde baskı oluşturmasıdır [6]. Buna rağmen insanların bilgiyi işleme hızları ne yazık ki makinaların bilgiyi üretme hızlarına yetişememiştir. Elimizde olan verinin çokluğuna rağmen, hala sadece iki gözümüz ve bir beynimiz bulunmaktadır [10]. $\mathrm{Bu}$ nedenle analistlerin daha da eğitimli olması ve bilgisayar bilimlerinin yanı sıra istatistik gibi alanlarda da bilgi sahibi olması gerekmektedir. $\mathrm{Bu}$ da sistem analisti yerine veri analisti kavramının gelişmesine olanak sağlamaktadır [10]. Veri 
analistleri sadece analiz yapmakla kalmayıp aynı zamanda önemli kararlara yön verebilmelidirler. $\mathrm{Bu}$ nedenle de gelecekte sistem analistinin rolü proje ekiplerinde problem tanımı ve analiz yapmak yerine daha çok strateji odaklı olacaktır [7]. İşletmelerin stratejilerine yön verip, işin mimarisinde, yönetiminde ve hatta işin ana dalında bile görev alacaklardır [7].

\section{Sistem Geliştirme Yaşam Döngüsü Așamalarında Kullanılan Yeni Yöntemler}

Sistem Geliştirme Yaşam Döngüsünün adımlarında yapılanlara değinirsek eğer; analistler planlama aşamasında sistemin geliştirilmesini isteyen kurumla görüşüp fizibilite çalışması yapmaktadırlar. Analiz aşamasında, sistemin işleyişi ve gereksinimleri belirlenip dokümante edilmektedir. Tasarım aşamasında, sistemin mimari tasarımı ve son kullanıcı için arayüz tasarımı yapılmaktadır. Ayrıca sistemin özellikleri belirlenmektedir. Kodlama ve test aşamasında ise sistem gerçekleştirilmektedir ve son aşama da ise sistem, bu sistemi sipariş eden kuruma teslim edilmektedir. Gelişen teknolojiyle beraber Sistem Geliştirme Yaşam Döngüsünün adımlarında da analistler tarafından yeni yöntemler kullanılmaya başlanmıştır veya başlanmalıdır. Aşağıda sistem analistlerinin aktif olarak rol aldıkları planlama, analiz ve tasarım aşamalarında analistlerin kullandığı ve ileride kullanması gereken yeni yöntemler incelenmiştir.

Globalleşen dünyada kurumlar farklı lokasyonlara yayılmışlardır. Bundan dolayı planlama aşamasında sistem analistleri internet ve mobil teknolojilerin gelişmesinden ve ucuzlamasından da faydalanarak yüz yüze toplantı yapmak yerine daha çok video konferans yöntemlerine yönelmişlerdir veya yöneleceklerdir. $\mathrm{Bu}$ sayede hem seyahat masraflarından hem de zamandan tasarruf edilecektir. Skype, Microsoft Lync, Netmeeting gibi yazılımlar video konferans yöntemlerini internet bağlantısı olan her bilgisayar ve mobil telefon için mümkün hale getirmiştir [11]. Bu nedenle de video konferans yönteminin kullanımı her geçen gün artmaktadır [11]. Ayrıca video konferans sırasında yapılan görüşmeler ve paylaşılan sunumlar kaydedilebilmekte ve bu da sistem analistlerine anlaşılamayan veya tekrar üzerinden geçilmesi gereken bir konu varsa o görüşmeye geri dönme imkânı sağlamaktadır.

Analiz aşamasında ise sistem analistlerinin doğru bir fizibilite çalışması yapabilmek için büyük veriyi anlaması ve analiz etmesi önem kazanmaktadır. Görüşmeler sonucu elde ettikleri bilgileri ve verileri sistemin tasarımını yapabilmek için çok iyi anlamlandırmaları ve analiz etmeleri gerekmektedir. Temel Bayes teorimi ve regresyon analizi veriyi analiz etmek için uygun yaklaşımlar olabilir ancak bunların ötesinde A/B Testi, küme analizi, veri madenciliği, makine öğrenmesi, doğal dil işleme, sinir ağları, ağ analizi, sinyal işleme ve zaman seri analizi gibi yöntemler de büyük veriyi analiz etmek için kullanılabilir [5]. Özellikle karmaşık sistemlerden elde edilen verilerin analizi için veriye dayalı modelleme ve hipotez üretme yöntemleri sistemin genel davranışını ve diğer sistemlerle etkileşimini anlamak ve bu sayede de veriyi analiz etmek için kullanılmaları gereken anahtar yöntemlerdir [12].

Analistler, büyük veriyi aynı zamanda analiz ettikleri birimdeki veya bölümdeki kişilerin nasıl çalıştıklarını ve hangi işlere daha çok vakit ayırdıklarını anlamak için de kullanabilmelidirler. Bunun için sensörler kullanılmalıdır [5]. Örneğin, çalışanların kimlik kartlarının içine takılan sensörlerle onların ne zaman ofise giriş-çıkış yaptıkları takip edilebilmektedir. Ayrıca eğer kurumun departmanları değişik katlara yayılmışsa her kata kapıların açılmasını sağlayan bir kart okuyucu konulmalıdır. Bu sayede de bir birey veya bir ekip beraber nasıl çalışıyor, ofisin içerisinde hareket ediyorlar $\mathrm{m} 1$ veya başka departmanlarla etkileşimli çalışıyorlar mı anlaşılabilir [5]. Büyük veri, sistem analistlerine, tüm şirket çalışanlarının veya çalışma gruplarının nasıl çalıştığını, ekip dinamiklerinin ne olduğunu, koordinasyon sorunlarının neler olduğunu ve performans sonuçlarının neler olduğunu daha kolay analiz etmelerine ve bunu temel alarak ilerisi için tahminler yürütmelerine olanak sağlamaktadır [5].

Analiz aşamasında sistem analistleri için en önemli noktalardan biri analistlerin tüm verilerin içinde kaybolmamaları ve hedef odaklı verileri kullanmalarıdır. Bunun için Hedef- Soru- Ölçüt [HSÖ] diye adlandırılan yöntem kullanılabilinir [13]. Analistler amaçlarına uygun hareket etmelidirler ve sadece kolay erişilebildiği veya düzenli olduğu için alınan veriler yerine amaçlarına uygun veriler hangileriyse onları toplamalıdırlar ve onlar üzerinde analiz yapmalıdırlar [13]. Ayrıca veri toplamadan önce hali hazırda bulunan verileri değerlendirmelidirler ve gerekirse yeni kaynaklardan veri toplamaya başlamalıdırlar [13]. Hedefleri ölçütlerle eşleyerek, sistem analistleri hangi verilerin ihtiyaçları karşılayabileceğini anlamalıdırlar. $\mathrm{Bu}$ sayede ihtiyaçları olmayan verileri toplamayarak zamanlarını ve enerjilerini verimli bir şekilde kullanmış olurlar [13].

Tasarım aşamasında, sistem analistleri planlama ve analiz aşaması kadar aktif rol oynamasalar bile yine de bu aşamada da görev almaları önemlidir. Tasarım aşamasında sistem analistleri için en önemli sorunlardan biri eğer büyük veri işleyecek bir sistem geliştirilecekse, bunun için gerekli olan 
altyapının oluşturulmasına dikkat etmektir. Örneğin, her gün Facebook yaklaşık olarak 500 terabayt büyüklüğünde kullanıcı verisi ve birkaç yüz terabayt büyüklüğünde de fotoğraf verisi işlemektedir [12]. Twitter ise dünya çapında 550 milyon aktif kullanıcıya hizmet vermekte ve bu kullanıcılar tarafindan toplamda her saniye 9100 tweet atılmaktadır [12]. Youtube'a da her dakika 100 saatlik video yüklenmekte ve 135,000 saatlik video izlenmektedir [12]. Eğer geliştirilecek sistem bunlara benzer büyüklükte veri işleyecekse donanımı da ona uygun şekilde yapılmalıdır. Değişken olmayan [Non-volatile] hafiza teknolojileri şu anda bu tip büyük veri işleyen sistemlerde kullanılmaktadır ve ileride de bu teknolojilerin daha çok gelişip önemli hale gelmesi beklenmektedir [12].

\section{Sonuç}

Bundan 40 yıl önce amaç, sistem geliştirmek için tüm dünyada ve tüm projelerde kullanılabilecek "o" sistem geliştirme modelini bulmaktı [14]. Fakat günümüzde ise bu amaç değişti ve bir projeden öğrenilen derslerin her zaman diğer projeler için de geçerli olamayabileceği anlaşıldı. Bu yüzden dünya çapında kullanılabilecek modeller yerine şu anki hedef yerel modeller geliştirmektir [14]. Bu nedenlerden dolayı yukarıda anlatılan yöntemler tüm projeler veya tüm sistem analistleri için geçerli olmayabilir. Sistem analistleri geliştirilecek sistemin ihtiyaçları doğrultusunda kendileri için en uygun olan yöntemleri yine kendileri belirlemelidirler. Ancak bu sayede etkili bir sistem geliştirmeyi başarabilirler.

$\mathrm{Bu}$ çalışmada internetin ve mobil teknolojilerin gelişmeye başlamasıyla beraber ortaya çıkan büyük veri kavramının sistem analistlerinin görevlerini nasıl etkilediği ve sistem analistlerinin görevlerinde ne gibi değişiklikler olduğu açıklanmaya çalışılmıştır. İlaveten, sistem analistlerinin Sistem Geliştirme Yaşam Döngüsü adımlarında kullanmaya başladıkları ve ileride kullanmaya başlamaları gereken yeni yöntemler üzerinde durulmuştur. Özellikle sistem analistlerinin aktif olarak rol aldıkları planlama, analiz ve tasarım aşamalarındaki yeni yöntemler anlatılmıştır. Yine de burada anlatılan yeni yöntemlerin tüm projeler için kullanılmaları gerekli olmayabilir. Sistem analistleri kendi tecrübelerine dayanarak $\mathrm{o}$ an üzerinde çalıştıkları proje için hangi yöntemleri kullanmalarının uygun olacağına kendileri karar vermelidirler.

\section{Kaynaklar}

[1] Misic, M. M., \& Graf, D. K. "Systems analyst activities and skills in the new millennium". Journal of Systems and Software, 71(1), 31-36, (2004).

[2] Butcher, H. "Information overload in management and business". Information Overload, IEE Colloquium on (pp. 1-1), (1995, Kasım).

[3] Feather, J. "Information Society: A Study of Continuity and Change". (1998).

[4] Weng, W. H., \& Lin, W. T. "Development Trends and Strategy Planning in Big Data Industry". Contemporary Management Research, 10(3), (2014).

[5] George, G., Haas, M. R., \& Pentland, A. "Big data and management".Academy of Management Journal, 57(2), 321-326, (2014).

[6] Edmunds, A., \& Morris, A. "The problem of information overload in business organisations: a review of the literatüre". International journal of information management, 20(1), 17-28, (2000).

[7] Robert Half Management Resources. "How Big Data Is Changing the Business Analyst Job Description".

URL:

http://blog.roberthalfmr.com/how-big-data-

changing-business-analyst-job-description (Erişim zamanı: Aralık 8, 2014).

[8] Katzer, J., \& Fletcher, P. T. "The Information Environment of Managers". Annual Review of Information Science and Technology (ARIST),27, 227-63, (1992).

[9] Badenoch, D., Reid, C., Burton, P., Gibb, F., \& Oppenheim, C. "The value of information". The value and impact of information, 9-78, (1994).

[10] Harvard School of Engineering and Applied Sciences. "Big Data Heralds a New Kind of Analyst". URL: http://www.seas.harvard.edu/news/2014/01/bigdata-heralds-new-kind-of-analyst (Erişim Zamanı: Aralık 8, 2014).

[11] Julsrud, T. E., Denstadli, J. M., \& Hjorthol, R. J. "Business Networking, Travel Tiredness, and the Emergent Use of Video Conferences". International Journal of Sustainable Transportation, 8(4), 262-280, (2014).

[12] Kambatla, K., Kollias, G., Kumar, V., \& Grama, A. "Trends in big data analytics". Journal of Parallel and Distributed Computing, 74(7), 2561-2573, (2014).

[13] Shull, F. "Data, Data Everywhere...". IEEE Software, (5), 4-7, (2014).

[14] Menzies, T., \& Zimmermann, T. "Software analytics: so what?".Software, IEEE, 30(4), 31-37, (2013). 